\title{
Capsule Commentary on Gahier et al., a Simple Scale for Screening Lower-Extremity Arterial Disease as a Possible Cause of Low Back Pain. A Cross Sectional Study Among 542 Subjects
}

\author{
Harpreet Singh, MD FACP ${ }^{1,2}$ \\ University of Pacific, Sacramento, CA, USA. \\ J Gen Intern Med 35(7):2250 \\ DOI: $10.1007 / \mathrm{s} 11606-020-05709-1$ \\ (c) Society of General Internal Medicine 2020
}

'General Internist, Sutter Gould Medical Foundation, Stockton, CA, USA; ${ }^{2}$ Adjunct Clinical Instructor Department of Physician Assistant Studies,

$\mathrm{T}$ his trial by Gahier et al. is a monocentric cross-sectional study in which authors studied the frequency and factors associated with exercise-induced peripheral ischemia (EIPI) in individuals with low back pain (LBP) and developed a screening scale that could help better select people requiring angiography. ${ }^{1}$

The study subjects were patients with ongoing LBP who were referred to an exercise investigation laboratory for exercise transcutaneous oximetry (ex-tcPO2). The study group turned out to be predominantly men with a mean age of 65 years. Authors defined EIPI as oxygen pressure below $15 \mathrm{mmHg}$ on the lumbar and/or buttock probes while exercising as compared with rest. Test was performed on a treadmill until symptom manifestation or exhaustion. It should be kept in mind that previous studies have established ex-tcPO2 as a reliable validated tool for diagnosing EIPI in comparison with arteriography and computed tomography angiography. ${ }^{2,3}$

Factors identified as EIPI predictors were age $\leq 70$ years, a history of proximal revascularization, use of antiplatelet medication, a relationship between exercise and LBP, and an abnormal ankle to brachial index. Using these items, a screening scale was developed. It was concluded that at a score of $\geq$ 3, the sensitivity, specificity, and accuracy for EIPI were 84\%, $55 \%$, and $71 \%$, respectively. One of the EIPI predictors, age less than 70 years was surprising and counter-intuitive. The author's explanation is that aging is associated with higher prevalence of comorbidities such as osteoarthritis that may become the main causes of low back pain superseding vascular reasons. One main limitation of the study was not including follow-up assessments, so no conclusions can be drawn on treatment efficacy, which could be done in future studies.

Clinicians can benefit from this study by using the screening tool to find more patients who can benefit from angiography and further revascularization. Total 17 patients went for revascularization in the study and their walking distances improved. As per authors, even when revascularization was not possible, the fact that the patients had a vascular origin of pain can be useful knowledge for the treating physician.

Corresponding Author: Harpreet Singh, MD FACP; General Internist Sutter Gould Medical Foundation, Stockton, CA, USA (e-mail: harpreet91@gmail.com).

\section{Compliance with Ethical Standards:}

Conflict of Interest: The author has no conflicts of interest with this article.

\section{REFERENCES}

1. Gahier M, Hersant J, Hamel JF, Sempore Y, Bruneau A, Henni S, Abraham P. A simple scale for screening lower-extremity arterial disease as a possible cause of low back pain. A cross sectional study among 542 subjects. J Gen Intern Med. (SPI 5670) https://doi.org/10.1007/s11606020-05670-z.

2. Abraham P, Picquet J, Vielle B, Sigaudo-Roussel D, Paisant-Thouveny F, Enon B, et al. Transcutaneous oxygen pressure measurements on the buttocks during exercise to detect proximal arterial ischemia: comparison with arteriography. Circulation. 2003;107(14):1896-900.

3. Henni S, Semporé YW, Le Meliner T, Ouedraogo N, Hamel J-F, Abraham P. Intra-test and test-retest reliability of exercise oximetry in arterial claudication. Microvasc Res. 2018;117:44-9.

Publisher's Note Springer Nature remains neutral with regard to jurisdictional claims in published maps and institutional affiliations.

Published online February 19, 2020 